\title{
Climatology and Variability of the Evaporative Stress Index and Its Suitability as a Tool to Monitor Australian Drought
}

\author{
HANH NGUYEN \\ Bureau of Meteorology, Melbourne, Victoria, Australia \\ JASON A. OTKIN \\ Cooperative Institute for Meteorological Satellite Studies, University of Wisconsin-Madison, Madison, Wisconsin \\ Matthew C. Wheeler, Pandora Hope, And Blair Trewin \\ Bureau of Meteorology, Melbourne, Victoria, Australia \\ Christa PuDMENZKY \\ Centre for Applied Climate Sciences, University of Southern Queensland, Toowoomba, Queensland, Australia
}

(Manuscript received 12 February 2020, in final form 11 August 2020)

\begin{abstract}
The seasonal cycle of the evaporative stress index (ESI) over Australia, and its relationship to observed rainfall and temperature, is examined. The ESI is defined as the standardized anomaly of the ratio of actual evapotranspiration to potential evapotranspiration, and as such, is a measure of vegetation moisture stress associated with agricultural or ecological drought. The ESI is computed using the daily output of version 6 of the Bureau of Meteorology's landscape water balance model [Australian Water Resource Assessment Landscape (AWRA-L)] on a 5-km horizontal grid over a 45-yr period (1975-2019). Here we show that the ESI exhibits marked spatial and seasonal variability and can be used to accurately monitor drought across Australia, where ESI values less than negative one indicate drought. While the ESI is highly correlated with rainfall as expected, its relationship with temperature only becomes significant during the warmer seasons, suggesting a threshold above which temperature may affect vegetation stress. Our analysis also shows that the ESI tends to be strongly negative (i.e., indicating drought) during El Niño and positive phases of the Indian Ocean dipole (IOD), when conditions tend to be anomalously hot and dry. A negative phase of the southern annular mode also tends to drive negative ESI values during austral spring with a one-month delay.
\end{abstract}

KEYWORDS: Australia; Drought; Seasonal cycle; Seasonal variability

\section{Introduction}

Tools such as the evaporative stress index (ESI; Anderson et al. 2011, 2013) and the standardized evaporative stress ratio (Christian et al. 2019) can be used to represent the combined influence of multiple meteorological and land variables on land surface moisture conditions that are relevant for agricultural and ecological drought. These variables include precipitation, air temperature, humidity, net surface radiation, wind speed, and soil moisture. The ESI has been found to be useful for monitoring drought over the contiguous United States (Anderson et al. 2007, 2013), Brazil (Anderson et al. 2016a), and the Czech Republic (Anderson et al. 2016b). It is currently used as an input to the U.S. Drought Monitor (M. Svoboda 2019, personal communication). The ESI is especially useful for monitoring rapidly intensifying drought, or flash drought, with examples from both the United States (Otkin et al. 2018a,b, and references therein) and Australia (Nguyen et al. 2019). Importantly, the ESI can provide information on the health of nonirrigated crops and pasture, and when computed with daily updated data, can also inform on rapid changes in drought conditions. Despite

Corresponding author: Hanh Nguyen, hanh.nguyen@bom.gov.au the apparent utility of the ESI, no studies have described the climatology and variability of the ESI over Australia, or their relationship to the main modes of variability influencing the Australian climate. Thus, the purpose of this study is to improve our understanding regarding the climatology of the ESI-both its annual cycle and its spatial variations-over Australia, based on a high spatial resolution gridded ESI database computed daily for the years 1975-2018. We will also examine the relationship between the ESI and atmospheric and land surface variables influencing drought, and its connection to the known modes of climate variability.

In terms of the climate drivers of drought, drought conditions across Australia are linked most strongly with extended periods of low precipitation but have also been linked to higher-than-normal temperatures (Nicholls 2004). The primary modes of climate variability influencing Australian rainfall and temperature on seasonal time scales are the El Niño-Southern Oscillation (ENSO), the Indian Ocean dipole (IOD), and the southern annular mode (SAM) (Risbey et al. 2009). El Niño and a positive IOD generally cause hotter and drier conditions across Australia (e.g., Meyers et al. 2007), while the effect of the SAM is seasonally and regionally dependent. Positive SAM is associated with dry conditions over 
(a) DJF

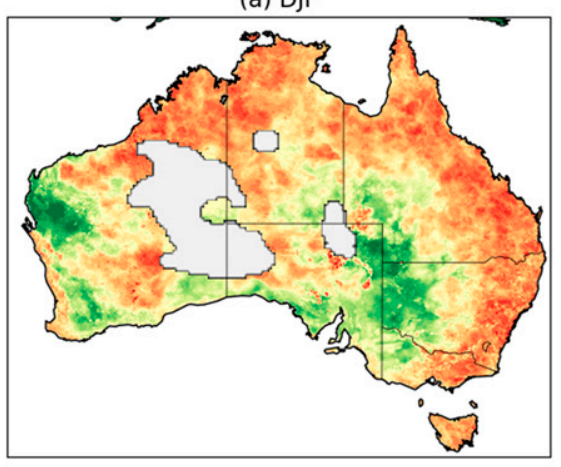

(c) JJA

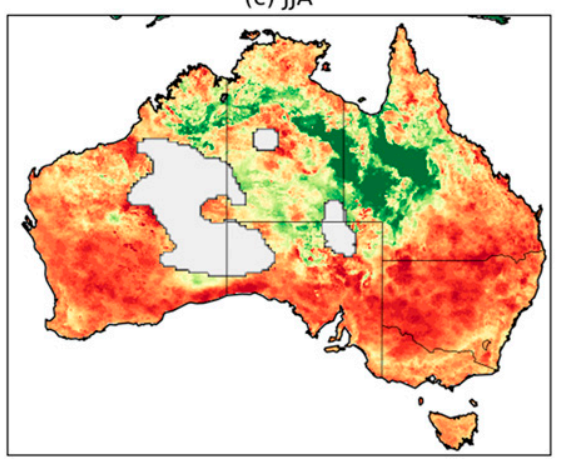

(b) MAM

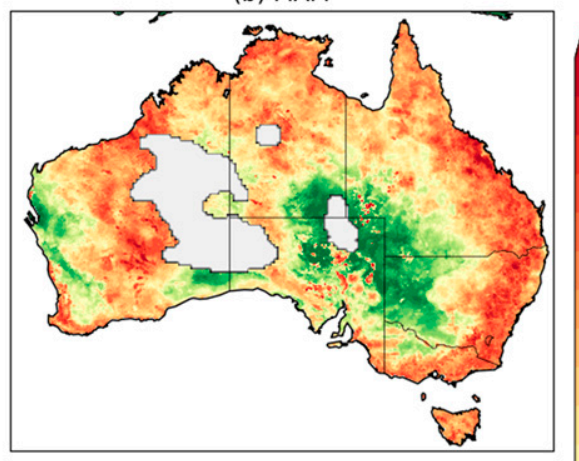

(d) SON

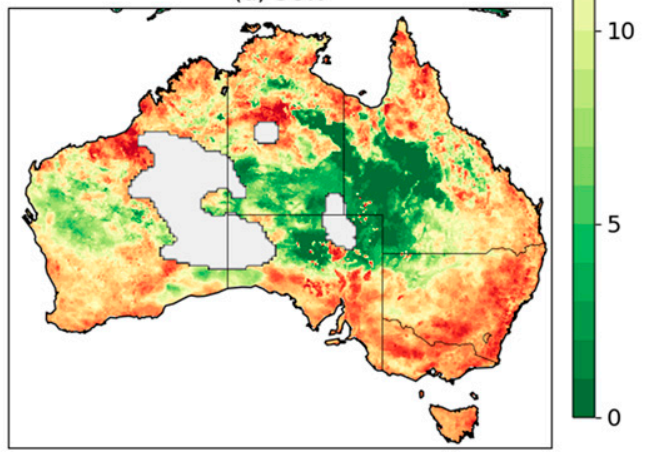

20

15

๖

FIG. 1. Seasonal frequency of occurrence of the daily ESI $<-1$ (ESIm1) expressed in percent of time for each season and for the period 1975-2018. The light gray areas indicate where there are insufficient observational data to reliably compute the ESI and are therefore masked out.

southwest Australia in autumn and winter, over the southeast in winter, and over Tasmania in winter and spring, but with wet conditions over the southeast in summer and spring (Hendon et al. 2007). Here we will examine the relationship between these climate modes of variability and the ESI.

The paper is organized as follows. Details of the datasets and analyses used in this study are provided in section 2 . Section 3 describes the climatology and variability of the ESI and its relationship with soil moisture, rainfall, temperature and the three modes of variability mentioned above. Section 4 presents the use of the ESI to detect drought occurrence in selected areas. Discussions and concluding remarks are given in section 5.

\section{Data and methods}

Here we use daily $5-\mathrm{km}$ gridded data interpolated from station observations from the Australian Water Availability Project (AWAP; Jones et al. 2009) and output from version 6 of the Bureau of Meteorology's land surface model [Australian Water Resource Assessment Landscape (AWRA-L); Frost et al. 2018]. The AWRA-L model takes observed inputs of precipitation, temperature, wind speed, solar radiation, and land surface type, and then produces a physically consistent description of the land water balance, with outputs of rootzone soil moisture (SM), evapotranspiration (ET), and potential evapotranspiration (PET). In the model, ET is the sum of evaporation (interception, soil, and groundwater) and transpiration (shallow and deep root water uptake and transpiration from groundwater). The PET is calculated according to the Penman equation as a combination of net radiation and vapor pressure deficit. Note that the ET and PET from AWRA are estimates and do not include direct measurements of the latent heat flux or modified pan evaporation, however, as shown by Nguyen et al. (2019), results align well with observed periods of extreme drying and give us confidence that these estimates of evapotranspiration do convey useful information.

The ESI is the standardized anomaly of the ET/PET ratio, computed independently at each grid point. These data are updated daily and are available in near-real time. We limit the period of study to $1975-2019$, noting that 1975 is when observation-based wind data are first introduced into AWRA-L. Prior to 1975, climatological wind speeds are used as input into AWRA-L, and prior to 1990, climatological radiation fields are used (Frost et al. 2018). However, the effects of radiation on the ESI are minor compared to those of the wind fields (Otkin et al. 2018a; Nguyen et al. 2019), therefore we choose to use data starting in 1975 in order to increase the length of the climatology. The ESI is calculated daily over a 4-week running window, with the date of a given window corresponding to the last day of that window. The standardization for the ESI is computed as 


\section{Climatological ESIm1}

(a) DJF

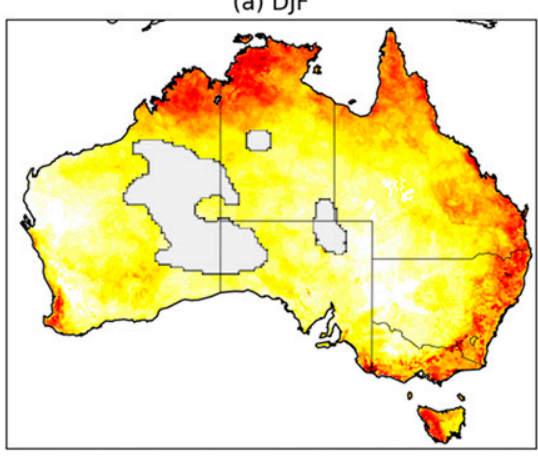

(c) JJA

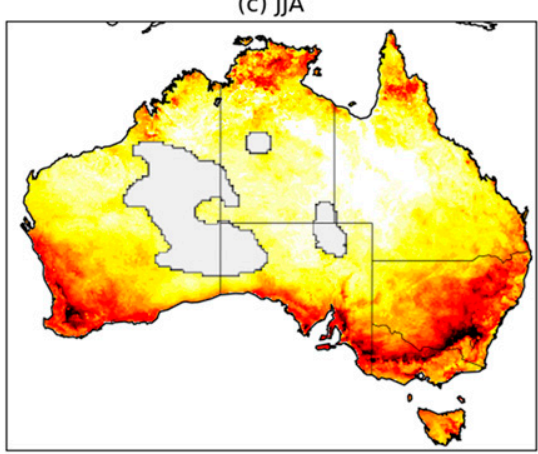

(b) MAM

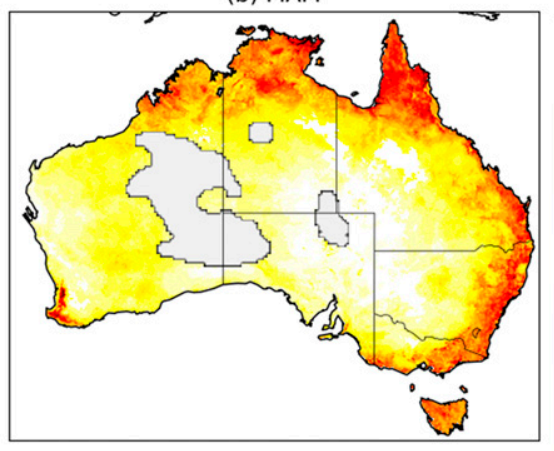

(d) SON

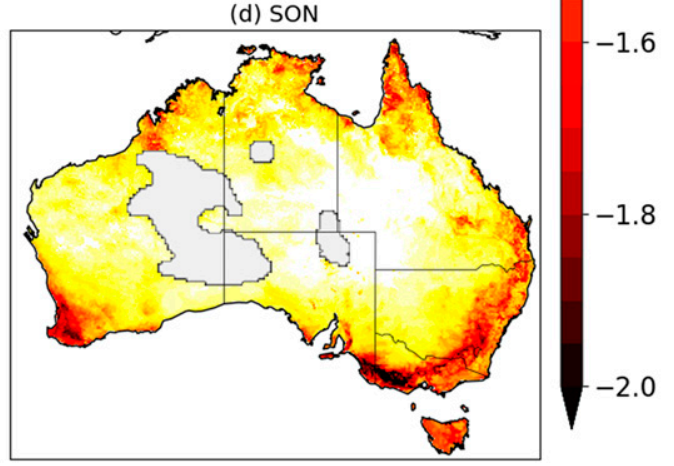

FIG. 2. Seasonal mean ESIm1 magnitude for each season and for the period 1975-2018, with areas of insufficient observation data masked out in light gray.

$$
\mathrm{ESI}=\frac{r_{\mathrm{ET}}-\overline{r_{\mathrm{ET}}}}{\sigma\left(r_{\mathrm{ET}}\right)},
$$

where $r_{\mathrm{ET}}=\mathrm{ET} / \mathrm{PET}$ is the ET fraction, and $\overline{r_{\mathrm{ET}}}$ and $\sigma\left(r_{\mathrm{ET}}\right)$ are its climatological mean and standard deviation, respectively, for that time of the year computed over the period 1975-2018. Note that 2019 was not included in the climatological mean because at the time of computation the year was not complete. Therefore, we fixed the climatology to 1975-2018.

Further details on the AWRA-L land surface model and the ESI computational technique can be found in Nguyen et al. (2019). Areas that lack enough in situ observations of precipitation and temperature to provide reliable estimates of the ESI are masked out in the figures presented in this paper. These areas generally have little, if any, agricultural production.

Standardized rainfall and temperature anomalies are calculated the same way as the ESI:

$$
V^{\prime}=\frac{V-\bar{V}}{\sigma(V)},
$$

where $V$ is the rainfall or temperature in this case and $V^{\prime}$ their standardized anomalies. These anomalies are also calculated over a 4-week running window at daily intervals using the 1975-2018 climatological reference period. As discussed in Nguyen et al. (2019), the standardization ensures that the seasonal dependence of the variables is put into a proper climatological framework.

In addition, monthly time series of the Niño-3.4 index, the dipole mode index (DMI) and the Marshall SAM index (SAMI) are used to investigate the association of the ESI with ENSO, IOD, and SAM, respectively. Both Niño-3.4 and DMI are derived from the HadISST dataset (Rayner et al. 2003) while the SAMI is derived from the zonal mean station sea level pressure difference between $40^{\circ}$ and $65^{\circ} \mathrm{S}$ (Marshall 2003). These time series were retrieved from the KNMI Climate Explorer web page in August 2019 (http://climexp.knmi.nl/selectindex.cgi? id=someone@somewhere).

Long-term seasonal trends of the ESI, rainfall and temperature are calculated over 44 years (1975-2018), and a two-tailed statistical significance $t$ test at the 95\% level is applied to the trends. Daily anomalies are used and all 4-week windows that fall in a given season are considered for the trend calculation for that season. However, for the trend the number of degrees of freedom we use to estimate the statistical significance is the total number of years rather than the total number of days for each season. That is, we make the conservative estimate of only one independent sample for each season per year.

Seasonal partial correlation coefficients between the ESI and the atmospheric and land surface variables are also calculated to examine their relative dependence. The correlations are based on daily anomalies and in each season there is at least 
(a) DJF

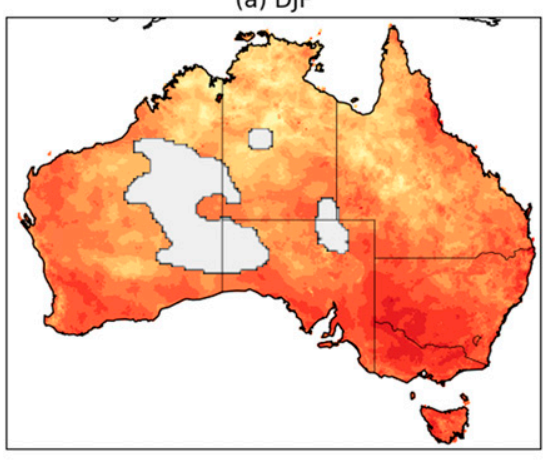

(c) JJA

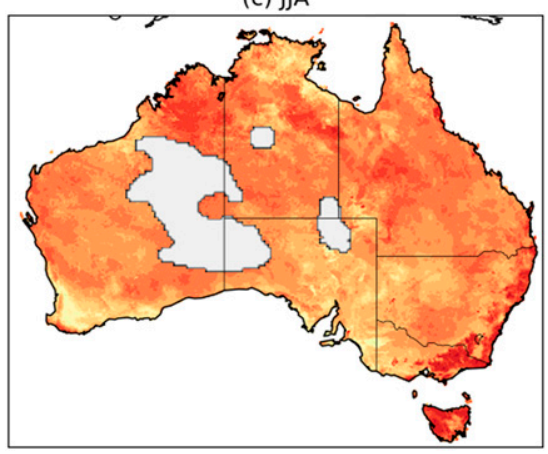

(b) MAM

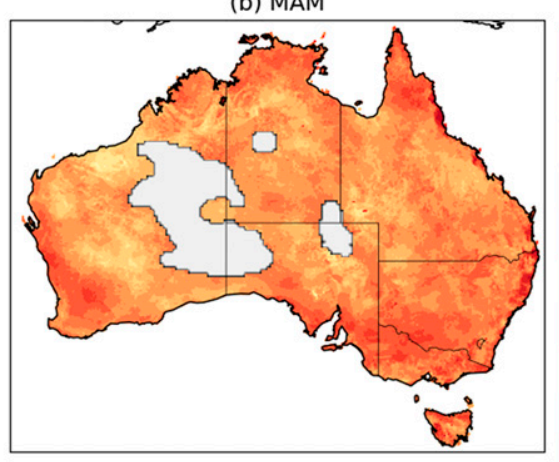

(d) SON

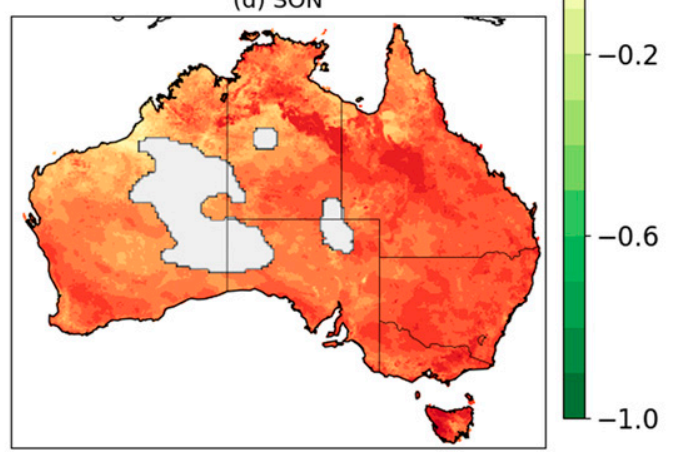

FIG. 3. Seasonal partial correlation of daily values between the ESI and rainfall anomalies, holding constant temperature anomalies. The $95 \%$ confidence level is for $r= \pm 0.17$ for a sample size of 44 years $\times 3$ months, and areas of insufficient observation data are masked out in light gray.

three independent 4-week window values. Therefore, the number of degrees of freedom $3 \times 44$ years is applied to assess statistical significance. The $95 \%$ confidence level defined by the $t$ test is applied to test the significance of the correlations.

Seasonal correlation coefficients are also computed between the ESI and Niño-3.4, DMI, and the SAMI. The $t$ test at $95 \%$ confidence level is applied to assess the significance of the correlations. Since the climate indices are monthly means, we first compute the monthly mean of the standardized anomalies of the ESI, rainfall, and temperature prior to computing the correlation coefficients. Therefore, there will be three values per season per year for the correlation coefficient calculation, and the degrees of freedom will be $44 \times 3$.

We also make use of the combined drought index (CDI) developed for the Australian Drought Monitor by the Northern Australian Climate Program (NACP, https:/www.nacp.org.au/) to assess the robustness of the ESI for monitoring drought. The Australian Drought Monitor is based on the U.S. Drought Monitor (USDM) concept. Here, the CDI is a scaled down version of the USDM, using only four selected indices to limit the impact of human opinion on its results. They are the standardized precipitation index (SPI), ET index, soil moisture deficit index (SMDI), and normalized difference vegetation index (NDVI). Each of the four datasets is percentile ranked over a baseline period and then the results are combined using a weighted average. Principal component analysis is used to determine the optimal weighting for the CDI for each grid cell $(5 \mathrm{~km} \times 5 \mathrm{~km})$ for every month over Australia (see Fig. A1 in the appendix). The CDI is calculated back to April 1992, which is when data for the NDVI began.

All seasons mentioned in this study are the austral seasons such that summer refers to December-February (DJF) and winter refers to June-August (JJA).

\section{Climatology and variability of the ESI}

\section{a. ESI frequency of occurrence}

By definition, the long-term average of the ESI is near zero because it is standardized. Therefore, to capture the part of the ESI that reflects drought conditions, we retain only values less than -1 (hereafter ESIm1) at each daily time step and for each grid point before computing the seasonal mean. If the ESI was normally distributed, then ESI $=-1$ would correspond to the 13.6th percentile, which ensures that drought conditions are captured. The seasonal mean frequency of occurrence of these defined drought conditions (ESIm1) and their associated magnitudes are displayed in Figs. 1 and 2, respectively. The magnitude here refers simply to the averaged ESIm1 values only.

The highest frequency of occurrence of drought conditions is located nearer the coasts and tends to peak during the wet/growing 
(a) DJF

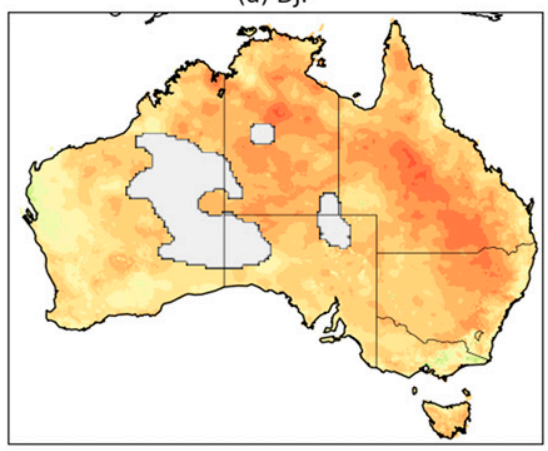

(c) JJA

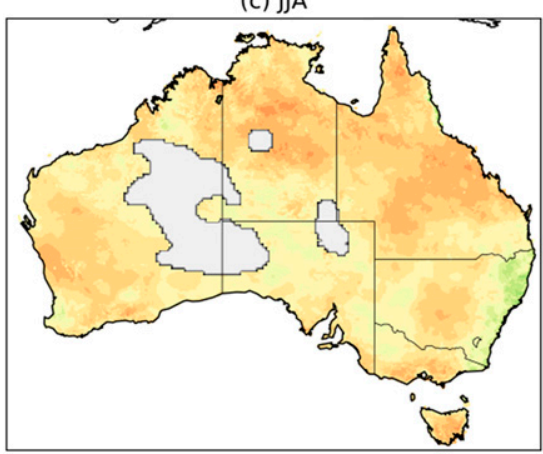

(b) MAM

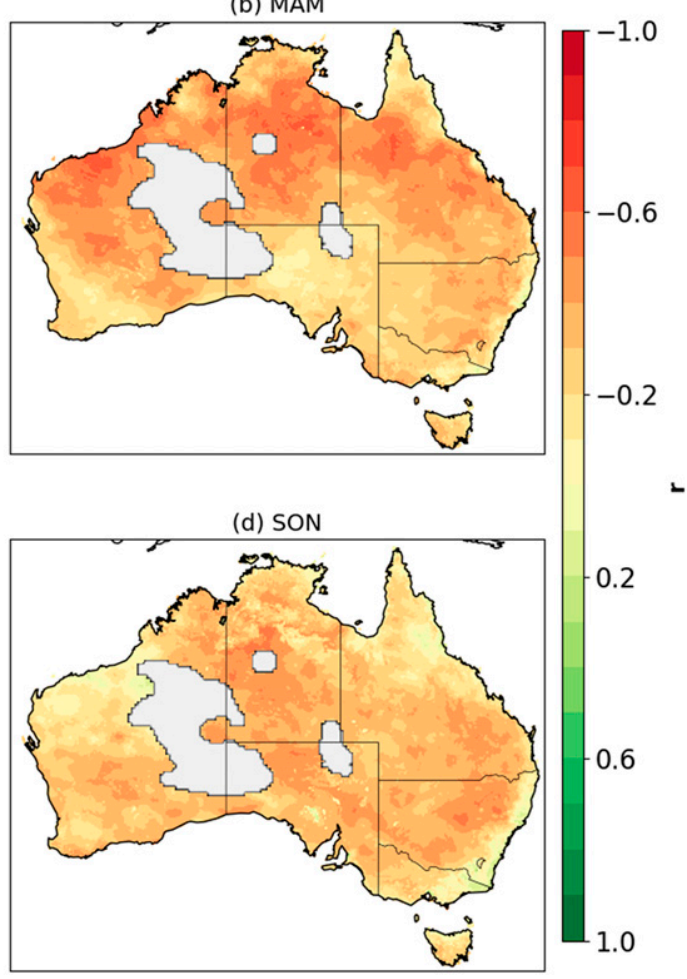

FIG. 4. Seasonal partial correlation of daily values between the ESI and temperature anomalies, holding constant rainfall anomalies. The $95 \%$ confidence level is for $r= \pm 0.17$ for a sample size of 44 years $\times 3$ months, and areas of insufficient observation data are masked out in light gray.

seasons, being in summer (DJF) in northern Australia and in winter (JJA) in the south (Fig. 1). In contrast, the lowest frequency of occurrence of drought conditions occurs inland and in the near-coastal Gascoyne region of Western Australia (WA) during the climatologically dry summer and autumn (MarchMay) period. The associated mean drought magnitude (Fig. 2) also shows marked seasonality and peaks toward the coasts. These peak drought values are strongest in summer in the north and in winter in the southeast and southwest. In contrast, both drought frequency of occurrence and magnitude are weak in the central desert regions all year round. This is because the distribution of ESI values is constrained in the negative direction by the fact that the ET can never be below zero. Therefore, in locations that are seasonally very dry, such as the central Australian deserts, with very little ET, the ESI may rarely, if at all, get below -1 . This is a useful characteristic of a drought index to have, since drought is less meaningful in locations and seasons that climatologically have almost no rain and no available moisture for ET. In those locations there will be fewer plants, and those that do survive will already be well adapted to the harsh seasonal conditions.

\section{b. ESI relationship with rainfall and temperature}

Nguyen et al. (2019) found that variations in rainfall were the main drivers of changes in the ESI during a flash drought that occurred over Australia from late 2017 to early 2018, while high temperatures exacerbated the drought severity. Here, we further investigate the relationship of the ESI with rainfall and temperature over the full climatological time period. Figures 3 and 4 show seasonal partial correlation coefficients between the ESI and standardized anomalies of rainfall and temperature, respectively. Unlike the frequency of occurrence shown in Figs. 1 and 2, here all of the ESI values (i.e., not just those $<-1$ ) are considered to account for the full relationship between variability in the ESI and the various atmospheric drivers.

There is a marked seasonality in these correlation coefficients, with the ESI more closely correlated with rainfall (Fig. 3) than with temperature (Fig. 4). This is indicated by the generally larger correlations for rainfall covering a greater portion of the continent. With rainfall, statistically significant correlation coefficients are observed across most of the country with magnitudes exceeding 0.5 . In contrast, the correlation coefficients for temperature are much weaker $(r<0.6)$ with larges areas not reaching the $95 \%$ confidence level. In the summer and autumn, the partial correlation patterns are complementary, with weaker correlations for rainfall in the north collocated with stronger correlations for temperature, and vice versa in the south. However, during the cool season, the relative relationships are similar with stronger correlation coefficients with rainfall collocated with those for temperature, 

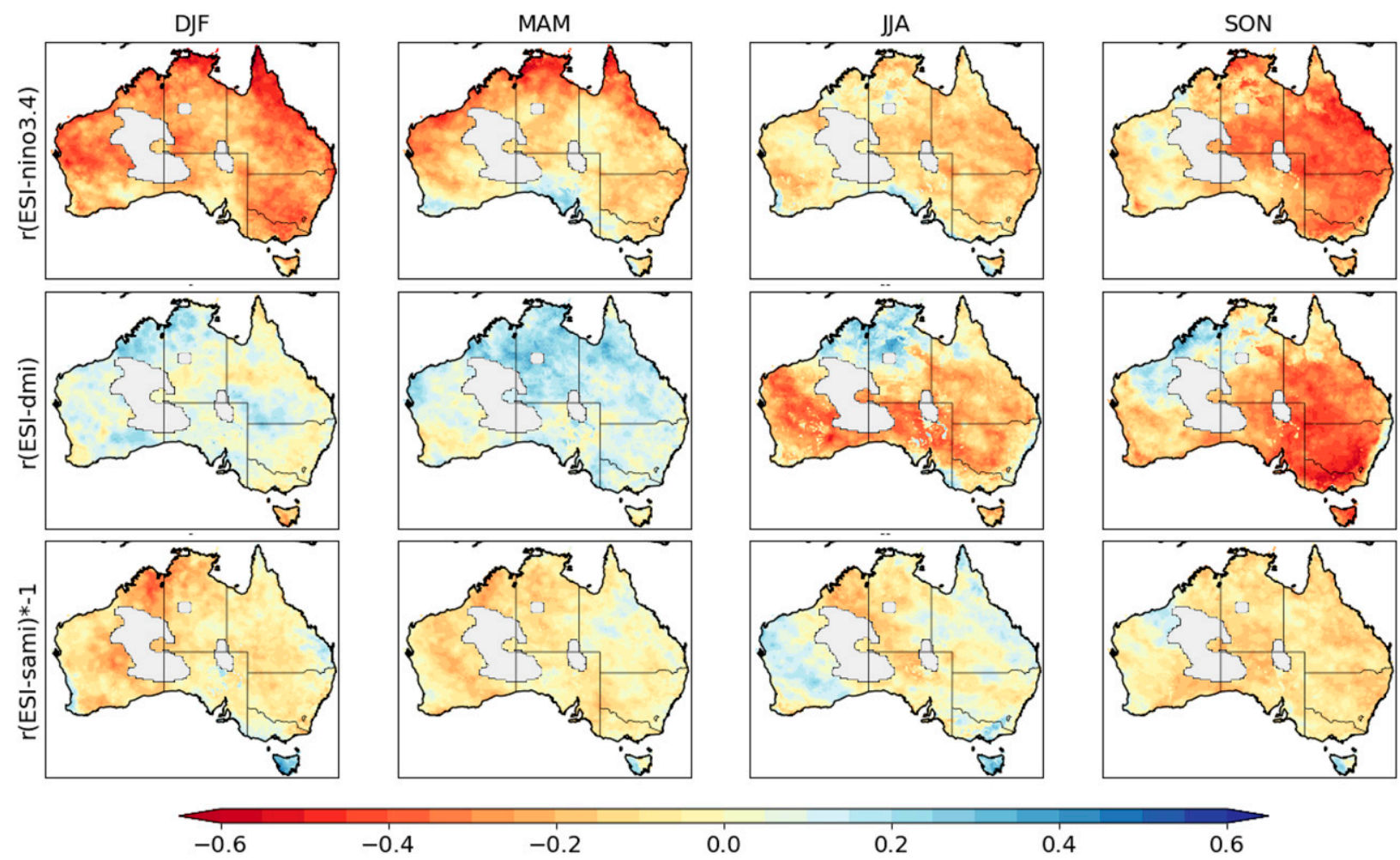

$-0.2$

0.0

0.2

0.4

0.6

FIG. 5. Seasonal correlation of monthly values between the ESI and Niño-3.4, DMI, and SAMI (reversed sign), respectively. The 95\% confidence level is for $r= \pm 0.17$ for a sample size of 44 years $\times 3$ months, and areas of insufficient observation data are masked out in light gray.

except along the southeast coastal stretch where high correlation coefficients with rainfall $(r>0.8)$ but hardly any relationship with temperature are observed. It is unclear what causes these localized high correlations. The much weaker correlations for temperature during the winter confirm that variations in temperature are less important for variations in ET due to the nonlinear relationship between the saturation vapor pressure and temperature (Schneider et al. 2010).

\section{c. ESI relationship with modes of climate variability}

Figure 5 displays seasonal correlations between the monthly mean ESI and the Niño-3.4, DMI and SAMI. The dominant correlation pattern is observed between Niño-3.4 and the ESI. Strong negative correlations $(r<-0.5)$ are seen across most of the country in spring and summer, in the east in spring, and along the northern coastal areas in autumn, indicating that drought is more likely to occur during El Niño (e.g., Santoso et al. 2019). Correlations with the DMI are only significant in winter and spring when the IOD is usually most active (Zhao and Hendon 2009). The strong negative correlations in the south-southwest during the winter and southeast during the spring suggest that a positive IOD favors drought development during those seasons.

Noting that the IOD and ENSO are correlated with each other, especially in winter and spring (Meyers et al. 2007), they each display very similar correlation patterns with the ESI.
Therefore, we remove this covariability between the DMI and Niño-3.4 in the correlations by way of a partial correlation analysis (Fig. 6, top two rows). The partial correlations show that in the absence of IOD, ENSO's influence on the ESI is mainly in the north-northeast regions whereas in the absence of ENSO, the IOD influence on the ESI is mainly in the southeast. This result is consistent with the partial correlation analysis with rainfall shown by Risbey et al. (2009).

The zero-lag correlation coefficients between the ESI and SAMI (Fig. 5, bottom row) are weak $(r<0.5)$ and scattered. Consistent with the relationship between the SAM and rainfall (Hendon et al. 2007; Risbey et al. 2009), positive correlations over mainland Australia indicate that drought conditions are more likely when the SAM is negative. In contrast, the correlations in Tasmania are mostly negative, indicating that a positive SAM is more likely to be associated with drought conditions. These relationships are strengthened when a onemonth lag is considered with the SAMI leading the ESI, as shown in Fig. 6. The positive correlations over mainland Australia during the spring become noticeably stronger and more extensive. This shows that a negative SAMI in AugustSeptember tends to lead to a stronger negative ESI in September-November and might offer avenues for early warning of drought intensification.

In summary, the ESI will tend to be more negative during El Niño throughout the entire year with the strongest signal in 

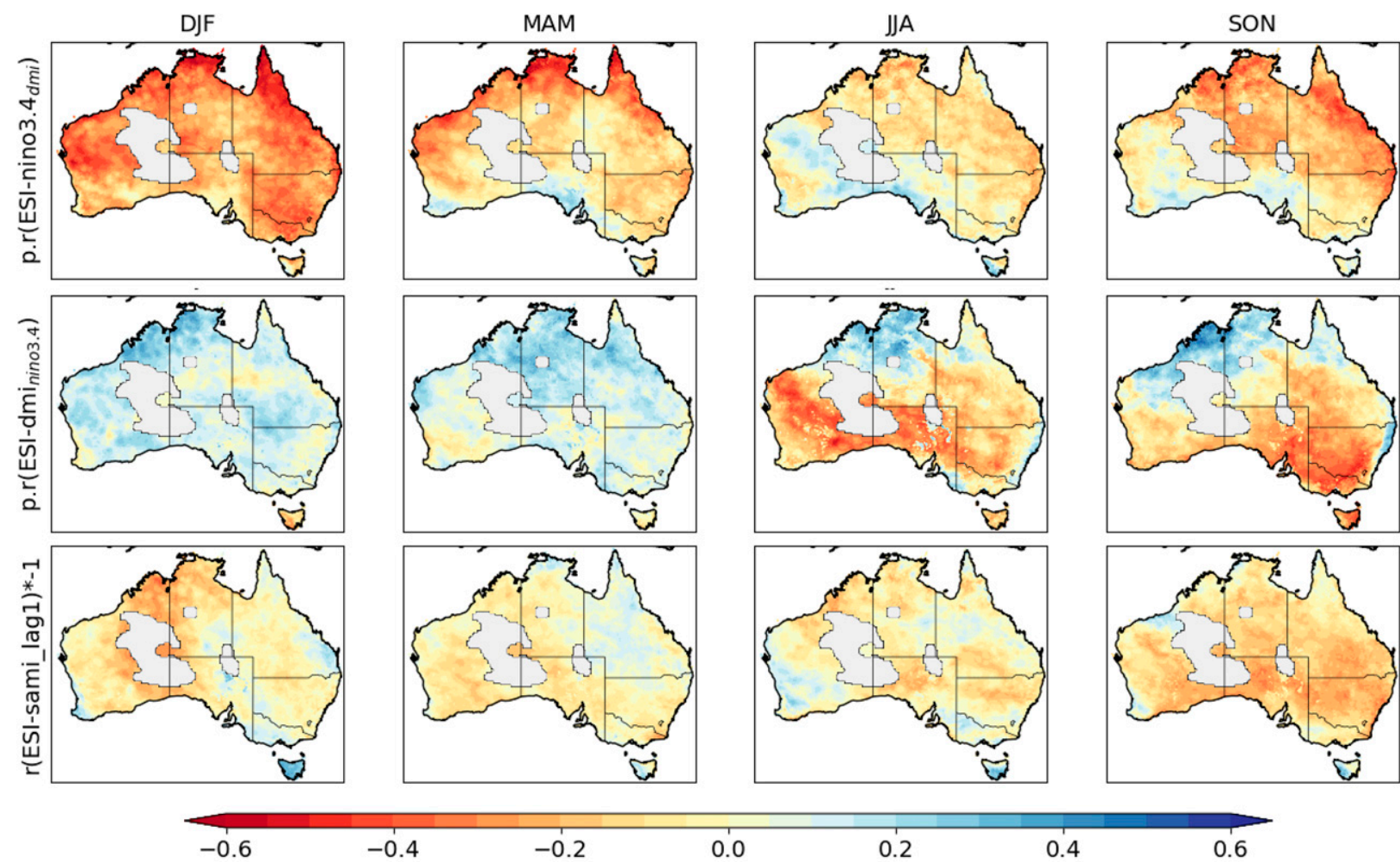

$-0.2$

0.0

0.2

0.4

0.6

FIG. 6. Seasonal partial correlation of monthly values between the ESI and Niño-3.4, (top) after removing the association with DMI and (middle) DMI, after removing the association with ENSO. (bottom) One-month lag correlation between the ESI and the SAM with the ESI lagging the SAM (reversed sign). The $95 \%$ statistical significance level is \pm 0.17 for a sample size of 44 years $\times 3$ months, and areas of insufficient observation data are masked out in light gray.

summer; during positive IOD in winter and spring; and during negative SAM in spring. This suggests that these climatic conditions are more favorable to drought occurrence and/or more severe drought events.

\section{d. ESI long-term trends}

Seasonal trends of the ESI, rainfall and temperature during the 1975-2018 time period are shown in Figs. 7-9, respectively. Statistically significant negative ESI trends occur mainly in east-central Australia during the winter, the southern half of Western Australia in the winter and spring, the south-southeast in the spring, and over Tasmania all year round. In contrast, positive ESI trends occur mainly in the western part of the continent and along the southern coastal strip in summer and autumn, and in the northwest region all year round. The magnitude of the trend peaks around $0.3 \sigma$ decade $^{-1}$. Assuming that the shape of the distribution of ESI values is not significantly changing with time, there is an implied increase in drought in the areas with a negative ESI trend, and a reduction in drought in those areas with a positive ESI trend.

Most of these ESI trends are collocated with consistent trends in rainfall. For example, the strong negative trend in ESI in South Australia, western New South Wales, and Victoria during the spring are collocated with a negative trend in rainfall (Fig. 8). However, Tasmania has a weakly positive rainfall trend in winter $\left(0.06-0.08 \sigma\right.$ decade $\left.^{-1}\right)$, despite having a negative ESI trend during that season. This contradiction may indicate that the shape of the distribution of ESI values might have changed in this area. We test the hypothesis by showing the ESI distribution in the first and second half of the period of study for the Natural Resource Management (NRM) ${ }^{1}$ clusters in Fig. A2. Indeed, four clusters show that in the latter half of the period, the ESI distribution is slightly negatively skewed, including the Monsoonal North West (MNW), the Southern Slopes Victoria West (SSVW), the Southern Slopes Tasmania East (SSTE), and West (SSTW). The last two clusters are located in Tasmania.

\footnotetext{
${ }^{1}$ Australia has 56 NRM regional boundaries defined by catchments and bioregions. These regional boundaries were grouped into "clusters" based on the larger-scale recent past climatic conditions and biophysical factors and with expected broad patterns of climate change by the NRM climate change report in Australia (CSIRO and Bureau of Meteorology 2015). Information on the regionalization method can be found on the Climate Change in Australia web page (https://www.climatechangeinaustralia.gov.au/ en/climate-projections/about/modelling-choices-and-methodology/ regionalisation-schemes/). See Fig. 11 for the cluster boundaries.
} 
(a) DJF

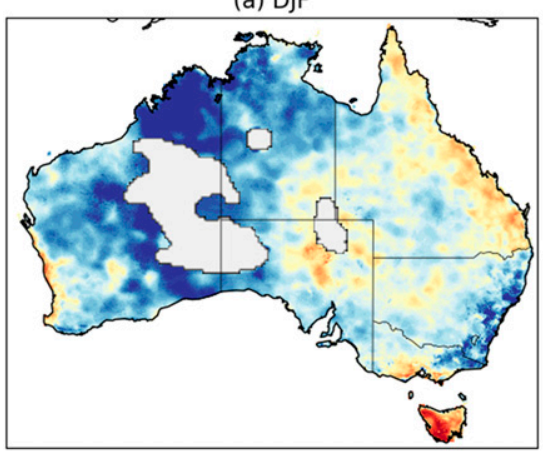

(c) JJA

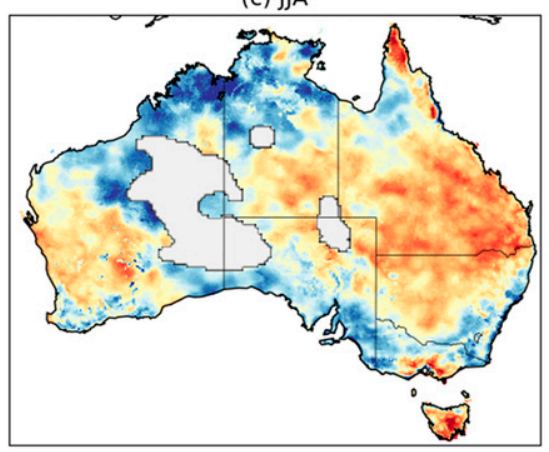

(b) MAM

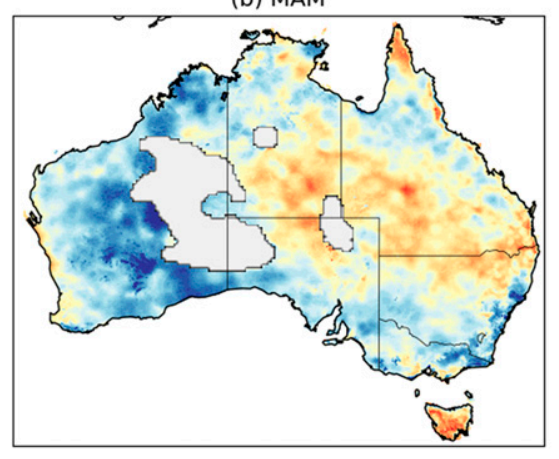

(d) SON

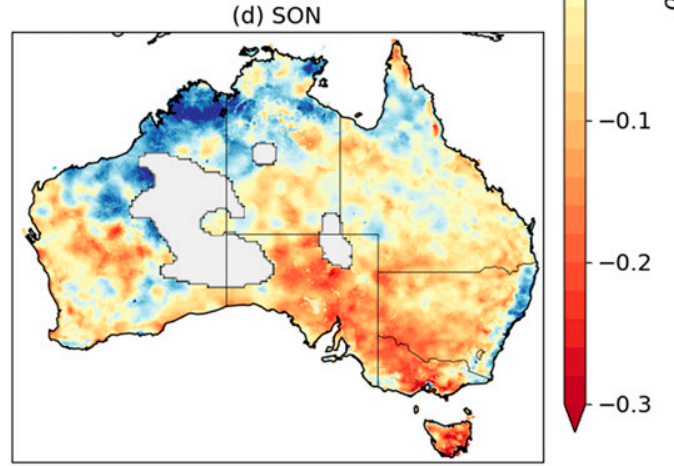

$-0.3$

0.2

$-0.1$

1 $\frac{\grave{d}}{\frac{0}{0}}$

FIG. 7. ESI seasonal trend for the period $1975-2018\left(\right.$ decade $\left.^{-1}\right)$. The $95 \%$ confidence level is for \pm 0.07 decade $^{-1}$, and areas of insufficient observation data are masked out in light gray.
Therefore, negative ESI trend there might just be due to the change in the distribution, not to an increasing rainfall deficit.

Temperature trends, on the other hand, are positive almost everywhere in all seasons, which is consistent with global warming of the climate (IPCC 2014). These warming trends are not as well collocated with the trends in the ESI, confirming that the influence of temperature on the ESI is not as strong as the influence of rainfall, except perhaps in southwestern Queensland in autumn and winter, where a strong positive trend in temperature is coincident with a strong negative trend in rainfall and in the ESI.

It is interesting to note that even though the spatial pattern of the ESI trend is more similar to that of the rainfall trend than that of the temperature trend, when negative rainfall trends are combined with positive temperature trends, the magnitude of the ESI trend is larger than if they oppose each other. This suggests that even though the regional ESI trends are more strongly tied to the trends in rainfall, the occurrence of drought in Australia is being amplified by the much warmer temperatures in recent years because the combined rainfall deficit and hotter temperatures exacerbate drier conditions through enhanced vapor pressure deficits.

In summary, we analyzed the climatology and variability of the ESI and its relationship to rainfall, temperature, and the known primary drivers of climate variability over Australia. The seasonality of occurrences of ESI $<-1$ was examined to provide an indication of its suitability for drought monitoring, and such occurrences were found to be more common in locations and seasons that were consistent with our prior expectations of drought. It was also demonstrated that the ESI relationship with rainfall, temperature, and the modes of climate variability fit with our expectations of drought.

\section{ESI as an index of drought}

In this section we go a step further and make a formal definition of drought based on the ESI. The ESI is a function of multiple factors including the moisture availability in the soil, in contrast to single factor indices such as the SPI (McKee et al. 1993; LloydHughes and Saunders 2002) that depends only on precipitation. Therefore, we expect the ESI to be a more complete/powerful drought index than such a single factor index, and potentially is comparable to the CDI. We verify this hypothesis showing partial correlation coefficients between the three indices in Fig. 10. The partial correlations using monthly data for the common period of all available data (1992-2019) clearly show that the SPI is weakly correlated with the CDI across the country, with strongest values below 0.5 in the southeast and Tasmania and scattered in the north. In stark contrast, the ESI is well correlated-with the partial correlation coefficients exceeding 0.6 , peaking at 0.9 along the southeast and southwest coasts and in eastern Tasmania. We also verified that the results remain robust with seasonal partial correlations (not shown). This confirms that the ESI is a robust drought index and clearly a much more robust index than the SPI. 
rainfall linear trend

(a) DJF

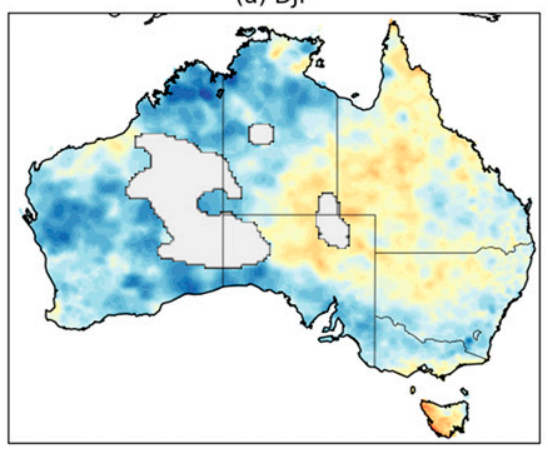

(c) JJA

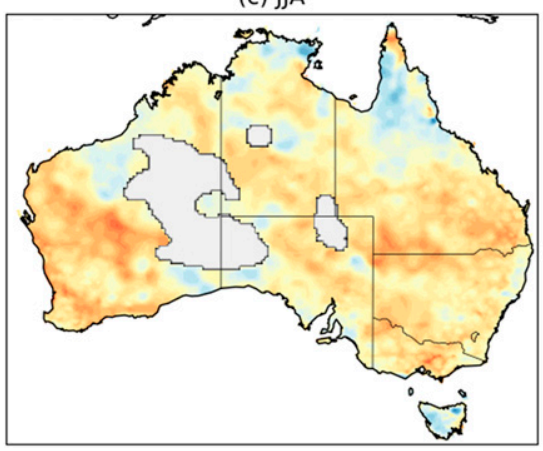

(b) MAM

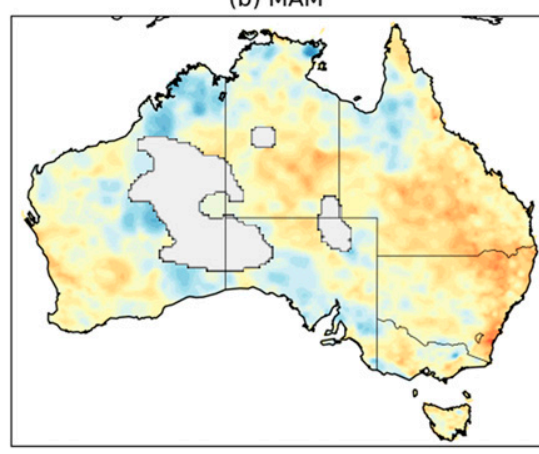

(d) SON

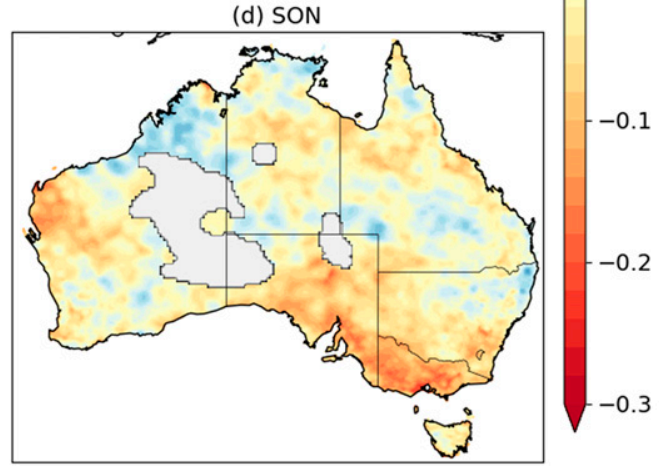

$-0.3$

$-0.2$

0.1

$\frac{0}{0}$

0.1

0.2

0.3

FIG. 8. Rainfall seasonal trend for the period 1975-2018 $\left(\right.$ decade $\left.^{-1}\right)$. The $95 \%$ confidence level is for \pm 0.07 decade $^{-1}$, and areas of insufficient observation data are masked out in light gray.

Important previous work on defining drought in Australia is that of CSIRO and Bureau of Meteorology (2015). Using a definition of drought based on the 12-month SPI, they reported that during the 20-yr period centered on 1995 (1986-2005) the time spent in drought in different clusters of NRM regions of Australia varied between $35 \%$ and $39 \%$. At the country scale and during that 20 -yr period the drought frequency per decade was 1.8 for moderate droughts, 1.5 for severe droughts, and 1.3 for extreme droughts, with the average drought duration for each drought category being 16, 21, and 26 months, respectively. To define these drought categories, CSIRO and Bureau of Meteorology (2015) used SPI thresholds from 0 to -1 for near normal, from -1 to -1.5 for moderate, from -1.5 to -2 for severe, and less than -2 for extreme drought. We use a similar methodology in this section, except with drought categories that are defined by thresholds of the ESI.

Here, the ESI is area averaged over a subset of 13 clusters of these NRM regions in order to monitor drought occurrence since 1975. Those regions are displayed in Fig. 11. Note that we left one large region (the Rangelands) blank on Fig. 11 because it includes the ESI areas that were masked and is dominated by deserts. The regions that have highly seasonal rainfall, and distinct "wet" and "dry" seasons [e.g., MNW and Southern and South-Western Flatlands West (SSWFW)] will not show drought during their dry season because the ESI anomaly is taken from a seasonal mean total. The 13 regions displayed in
Fig. 11 include areas where the population density is greatest and therefore the water demand is the highest. They also are collocated with the highest frequency of occurrence and intensity of the seasonal cycle of drought conditions (Figs. 1 and 2 ). The resulting ESI time series averaged over the 13 regions are shown in Fig. 12. Based on these features, we define a drought event when all of the following five conditions are met:

(i) Start date: the first time ESI $<0$.

(ii) Duration: the difference between end date and start date of at least 180 days.

(iii) Severity: determined based on the mean ESI value over the full duration of the drought event that is indexed from 0 to 4 such that

$$
\text { cat }= \begin{cases}0, & \text { for }-0.3 \leq \mathrm{ESI}<0 \\ 1, & \text { for }-0.8 \leq \mathrm{ESI}<-0.3 \\ 2, & \text { for }-1.2 \leq \mathrm{ESI}<-0.8 \\ 3, & \text { for }-1.5 \leq \mathrm{ESI}<-1.2 \\ 4, & \text { forESI }<-1.5\end{cases}
$$

These threshold values are the lowest 40th, 20th, 10th, and 5 th percentiles obtained from the ESI time series of the 13 NRM region clusters over the entire period of study, 
(a) DJF

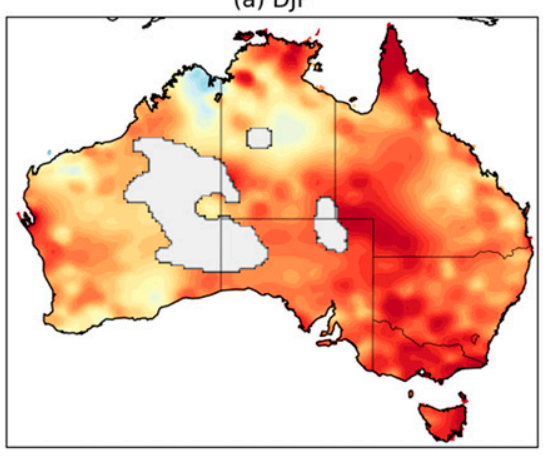

(c) JJA

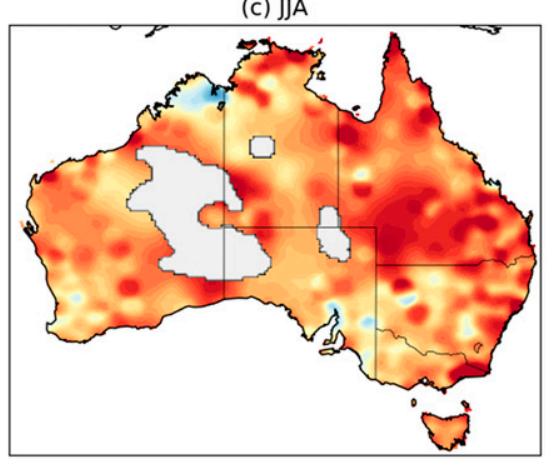

(b) MAM

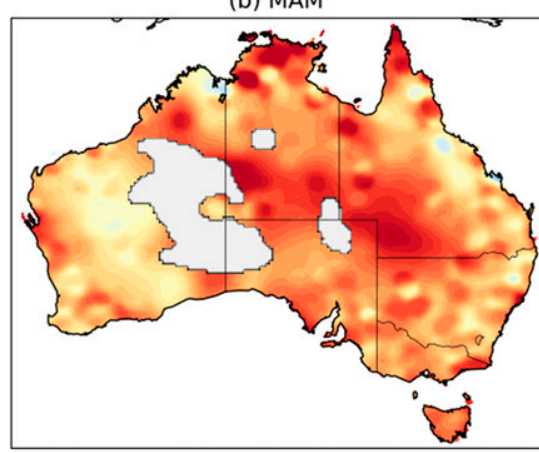

(d) SON

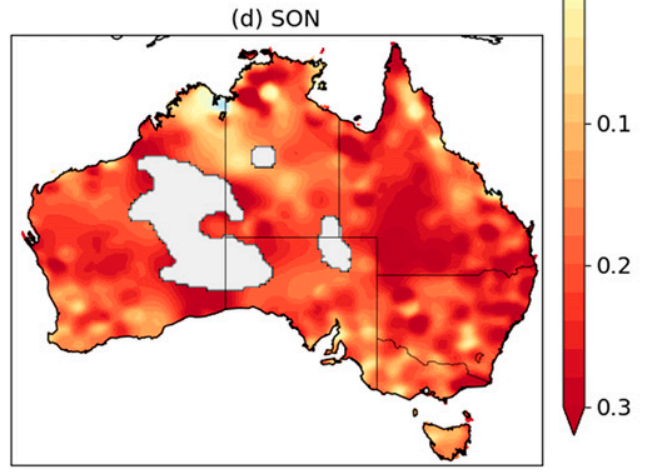

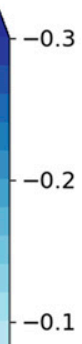

$0.0 \frac{\frac{2}{0}}{0}$

1

2

3

FIG. 9. Temperature seasonal trend for the period 1975-2018 $\left(\right.$ decade $\left.^{-1}\right)$. The $95 \%$ confidence level is for \pm 0.07 decade $^{-1}$, and areas of insufficient observation data are masked out in light gray.

rounded to one decimal place, respectively. Similarly to the USDM scale, 0 corresponds to abnormally dry, 1 to moderate, 2 to severe, 3 to extreme, and 4 to exceptional drought

(iv) End date: the last time ESI $<0$.

(v) If the interval between two consecutive drought events is less than 7 days, those are merged into a single event. This assumes that a recovery of 7 days or less between two drought events is too short to relieve the impact on agriculture.

The drought occurrence and severity defined in this way for each of the 13 NRM regional clusters are shown in Fig. 13. Inspection of Figs. 12 and 13 shows that a number of major drought events are noticeable in various regions as indicated by episodes of strong negative ESI values well below -1.5 (Bureau of Meteorology 2006, 2019):
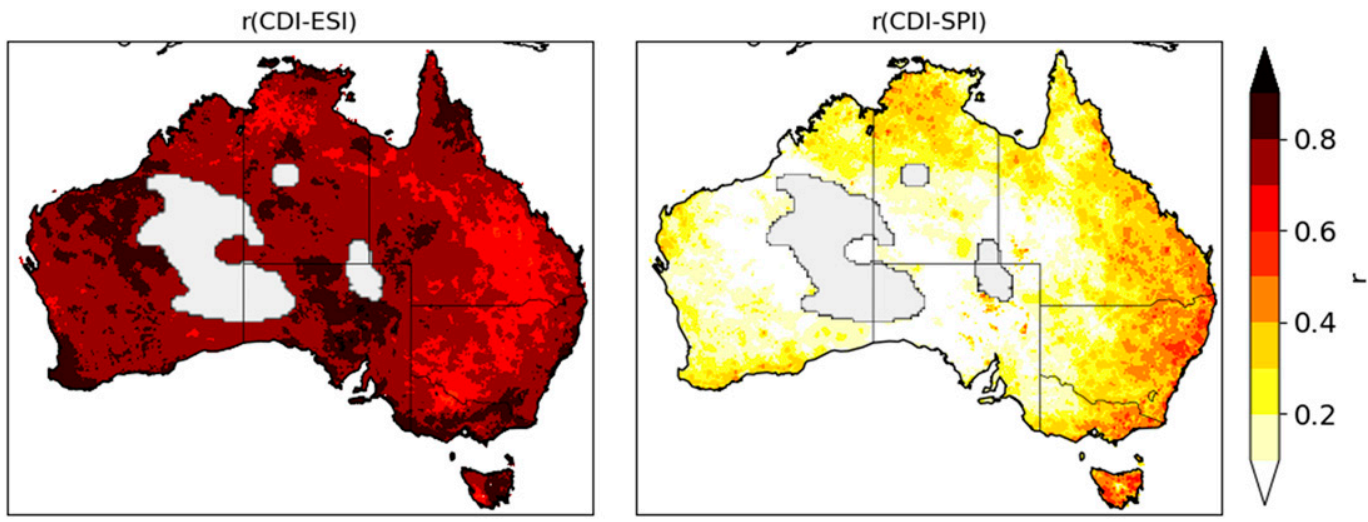

FIG. 10. Partial correlation of all monthly values between the CDI and ESI, (left) after removing the association with SPI and (right) SPI, after removing the association with the ESI. The period used for the computation is 1992-2019, therefore the sample size is 336 monthly values used to perform the correlation calculation. 


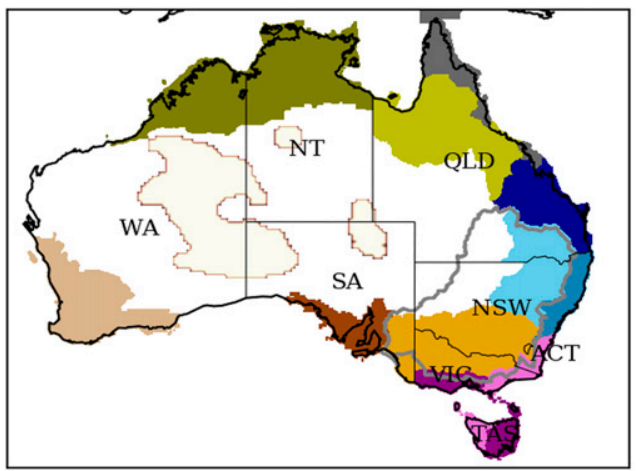

Wet Tropics (WT)

Monsoonal North East (MNE)

Monsoonal North West (MNW)

East Coast North (ECN)

East Coast South (ECS)

Central Slopes (CS)

Murray Basin (MB)

Southern Slopes Victoria East (SSVE)

Southern Slopes Victoria West (SSVW)

Southern Slopes Tasmanie East (SSTE)

Southern Slopes Tasmania West (SSTW)

Southern and South-Western Flatlands East (SSWFE)

Southern and South-Western Flatlands West (SSWFW)

FIG. 11. Map showing the 13 clusters of NRM regions using a unique Australian regionalization scheme taken from https://www.climatechangeinaustralia.gov.au/en/climate-projections/about/modelling-choices-and-methodology/ regionalisation-schemes/. The gray contour indicates the Murray-Darling Basin (MDB). The six states and two territories are indicated on the map by their acronyms: Western Australia (WA), Northern Territory (NT), Queensland (QLD), South Australia (SA), New South Wales (NSW), Victoria (VIC), Australian Capital City (ACT), and Tasmania (TAS).

(i) The 1982-83 short and severe drought associated with a strong El Niño that affected most of eastern and northern Australia.

(ii) The 1991-95 long El Niño-driven drought that affected the tropical north and central regions, and southern Queensland and northern New South Wales, extending at times to other parts of Australia.

(iii) The 2001-09 Millennium Drought that affected most of eastern and southern Australia, (iv) The 2013-15 drought which affected large areas of Northern Territory, Queensland, and northern New South Wales, as well as western Victoria and Tasmania. Note that the areas further inland in Queensland and northern New South Wales, in the Rangelands region, were also badly affected by this drought.

(v) The 2017-19 drought initially affecting eastern Australia before extending to most of the country by 2019. This was a

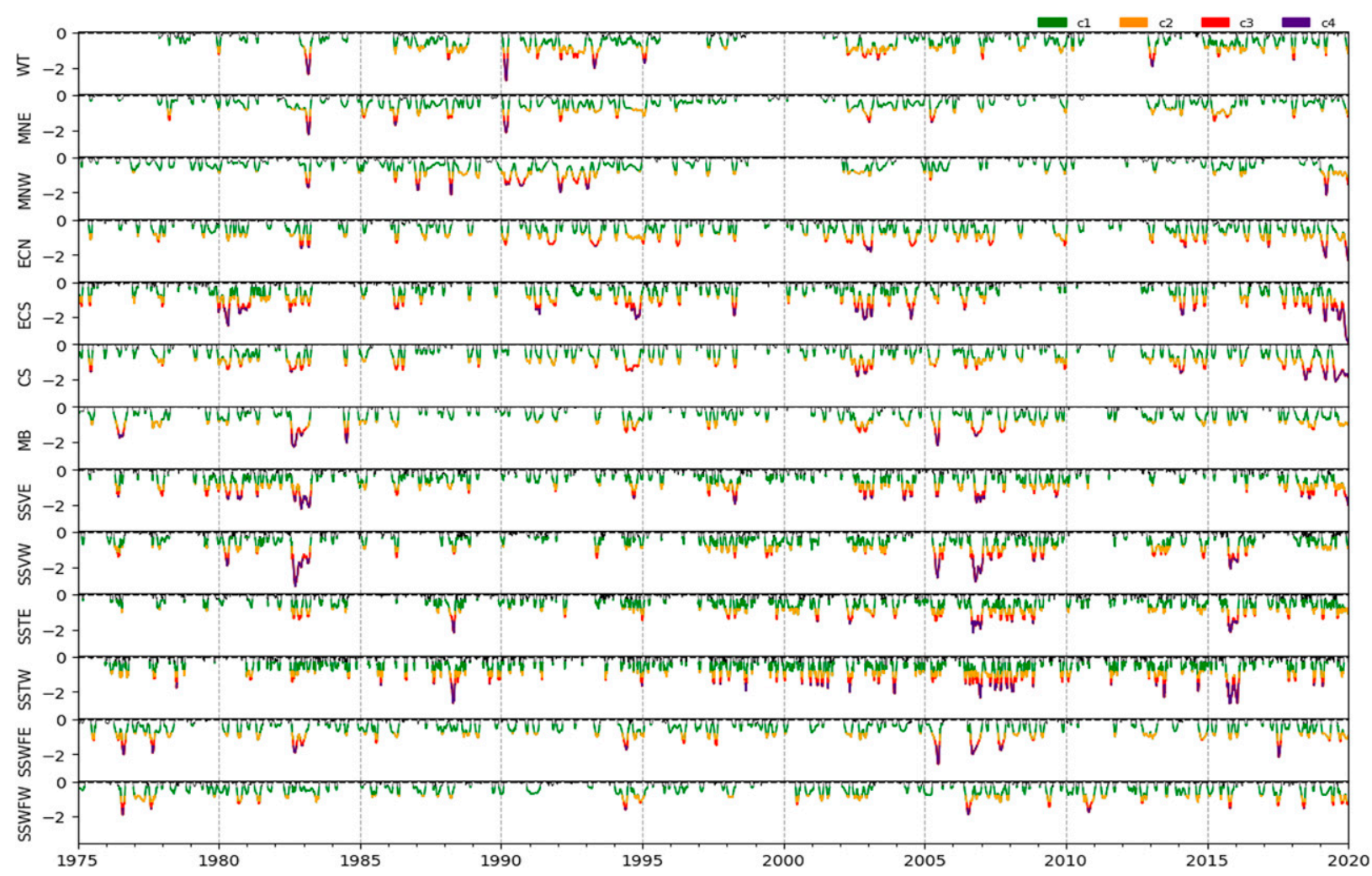

FIG. 12. ESI time series for each of the clusters of NRM regions. Thresholds indicating drought severity classifications c1-c4 are shown in dashed lines, and values below these thresholds are marked in green, yellow, orange, and red, respectively. 


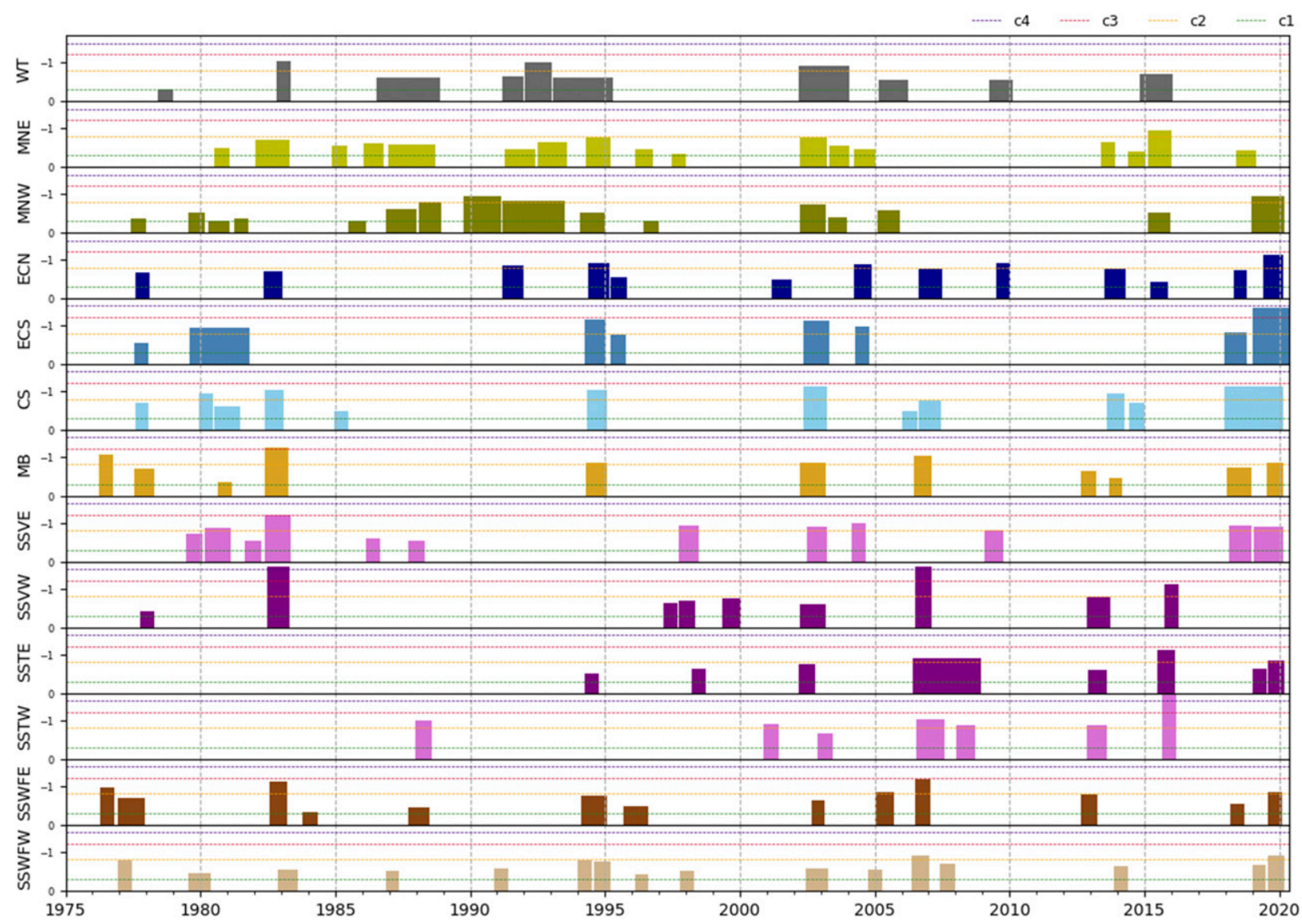

FIG. 13. Drought occurrences for each of the clusters of NRM regions. The thickness of the bars reflects the duration of each drought event, and their intensity defined as the mean ESI over the duration of the event is indicated on the $y$ axis. Drought severity classification thresholds $\mathrm{c} 1-\mathrm{c} 4$ are displayed in dashed lines.

particularly extreme drought, with the Murray-Darling Basin having its driest year on record in 2019, as did Australia as a whole.

Climatological drought occurrences over 1975-2019 are summarized in Fig. 14. The drought frequency varies between 1.5 (SSTE) and 3.8 [Monsoonal North East (MNE)] events per decade, the drought duration varies between 216 days (7 months) in SSWFW and 642 days (21 months) in Wet Tropics (WT), and the drought severity varies between moderate and severe. This represents an average over all clusters of 2.5 drought events per decade, with an average duration of 320 days (11 months). Compared to the CSIRO and Bureau of Meteorology (2015) mentioned above, the 45-yr period here shows a slightly higher frequency $\left(2.5\right.$ decade $^{-1}$ compared to 2.3 decade $^{-1}$ ) but a much shorter duration (11 months compared to 21 months). The latter difference can be explained in terms of the different definitions used. In the technical report, monthly mean SPI values computed over a 12 -month window were used, which would rule out all of the shorter duration droughts, and the end date was defined as the first positive SPI value after a value of -1 or less. In contrast, we use the 4 -week window ESI at daily time scale and define the end date as the last negative ESI value. This definition would lead to detection of more drought events. However, to date there is no official reported data on drought records over Australia to assess the validity of our method. We therefore leave any refinement options to future work.

\section{Discussion of results and concluding remarks}

An analysis of the seasonal cycle of the ESI computed from high-resolution gridded daily ET and evaporative demand over Australia highlights clear seasonal and spatial variability. The relationships between the ESI and rainfall and temperature are also seasonally and regionally dependent. In particular, drought as measured by the ESI has been more common in southern Australia during the winter and in northern Australia during the summer and autumn, and the most severe droughts have occurred in the far southwest and southeast portions of mainland Australia in winter and spring. While the ESI is suitable for monitoring flash droughts (Otkin et al. 2018a), we showed here using a 45-yr climatology that the ESI can also detect more conventional droughts for any region of Australia with sufficient observational data availability. These results are consistent with those found for the United States by Anderson et al. (2007, 2013) and Otkin et al. (2018b), for Brazil by Anderson et al. (2016a), and for the Czech Republic by Anderson et al. (2016b). 
drought statistics $1975-2019$ based on ESI
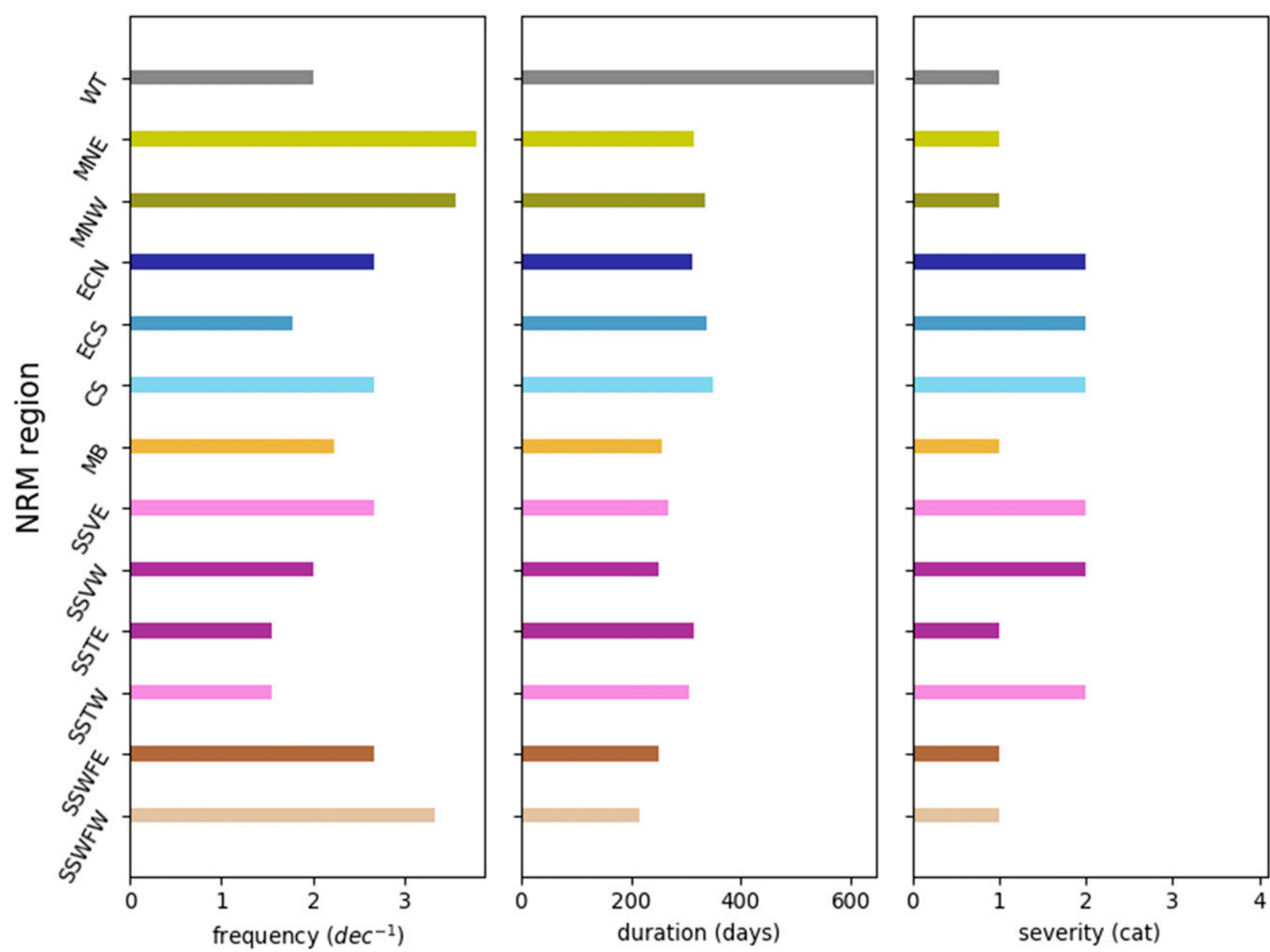

FIG. 14. Climatological drought occurrence for each of the clusters of NRM regions over the period 1975-2019 based on the ESI characterized by their (left) average frequency (number of events per decade), (center) duration (days), and (right) severity (drought category classification).

Given the significant impact of ENSO and the IOD on Australian climate, which tends to be warmer and drier than normal during El Niño and when the IOD is positive, here we show that the ESI is also strongly influenced by these modes of climate variability. In particular, negative ESI anomalies are enhanced during El Niño episodes throughout the year but more strongly in spring and summer, and during positive IOD in winter and spring when the IOD is active. Partial correlations further suggest that the impact of El Niño on the ESI is more prominent in north-northeast regions while IOD impacts on the ESI are more concentrated in the southeast of Australia, in both cases, leading to more favorable conditions for droughts to occur. Our results further suggested that a negative SAM in August-October may lead to enhanced negative ESI across much of eastern Australia from September-November. More refined lagcorrelation analysis suggests that a negative SAM in October leads to increased negative ESI in November for that region (not shown).
In the context of ongoing climate change that is directly affecting Australian rainfall and temperature (Reisinger et al. 2014), a long-term trend analysis was conducted. Significant negative ESI trends are evident in southern and eastern regions including Tasmania, while positive trends are observed in the

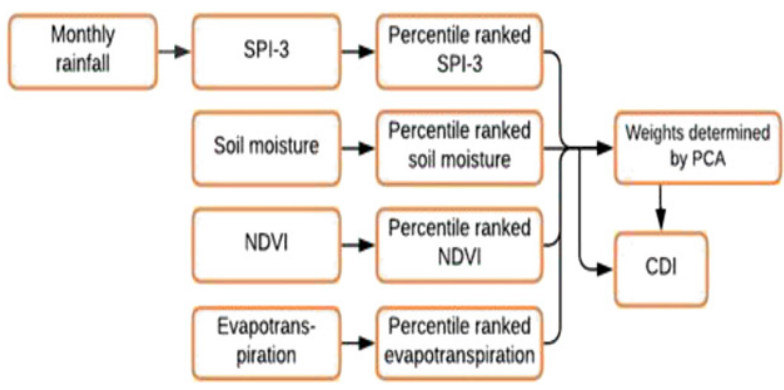

FIG. A1. An overview of the steps involved in producing the Australian CDI from the four input datasets. 


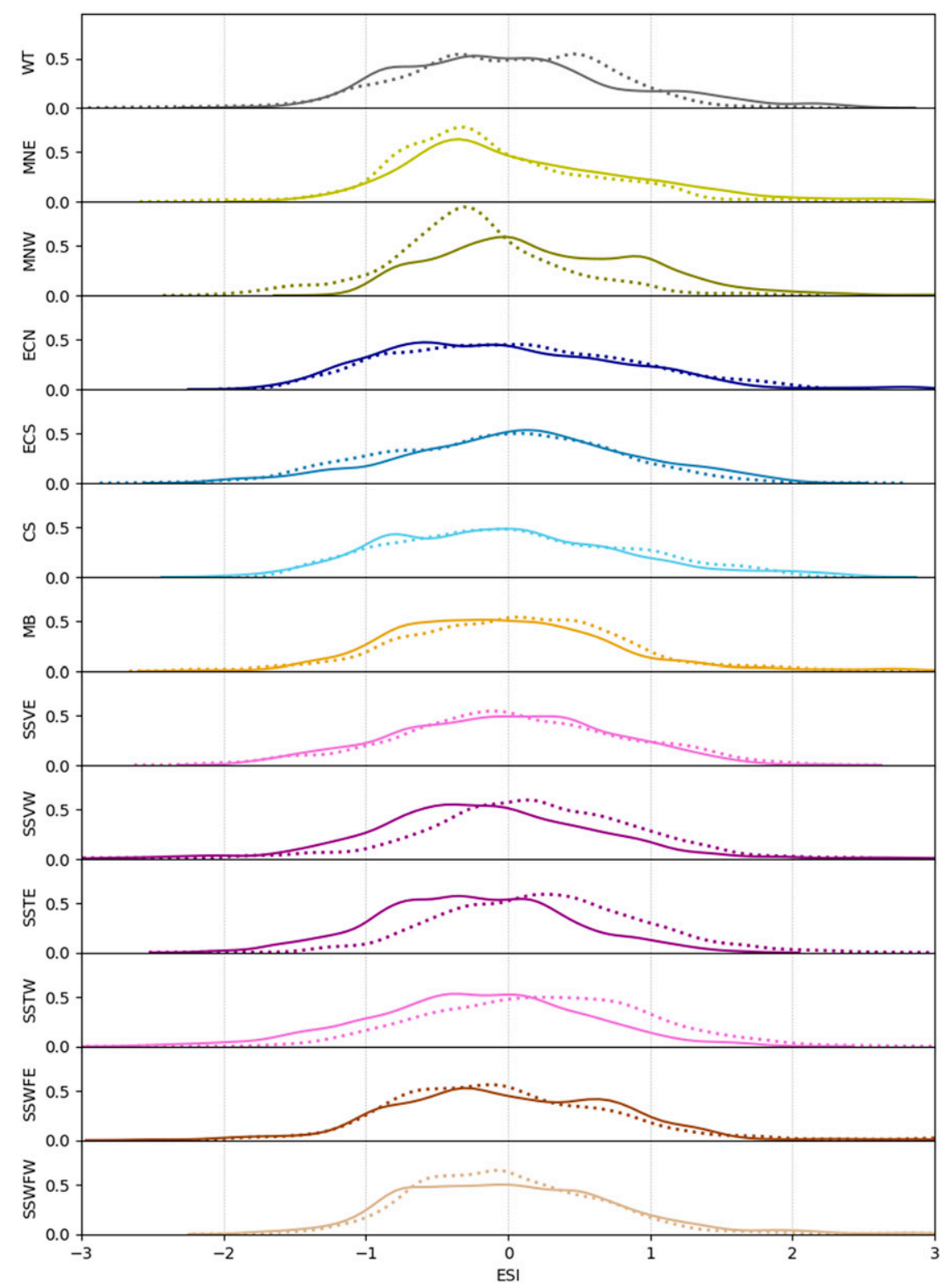

FIG. A2. Density distribution of the ESI for the NRM clusters over the 1975-96 period (dotted) and the 1997-2018 period (solid). See Fig. 11 for the cluster boundaries.

northwest. These trends are generally consistent with those in rainfall, but not always with temperature where a strong warming trend dominates across Australia. However, a combined rainfall deficit trend and warming trend act together to more negative ESI trends, consistent with the idea that a rainfall deficit is the main ingredient for drought while hot temperatures exacerbate the drought conditions, similarly to the effects of near surface wind speeds on droughts (McVicar et al. 2012).

The ESI has been successfully used to detect droughts over the 13 clusters of NRM regions for the 45 years. The drought statistics based on the ESI are comparable with the 20-yr baseline climatology reported in CSIRO and Bureau of
Meteorology (2015), and highlighted the historical major agricultural droughts reported by the Bureau of Meteorology (2006, 2019). Full characterization of drought in terms of occurrence, duration and drought severity shows that these events are quite frequent and tend to be severe. There is evidence of the impacts of these agricultural droughts across many sectors and ecosystems, for example the extensive dieback of the mangroves on the coast of the Gulf of Carpentaria at the end of 2015 (Duke et al. 2017) aligns with the drought occurrence across the three tropical regions (Fig. 13).

This is the first study that has examined the seasonal cycle of the ESI based on a 45-yr daily 5-km gridded observation and land surface modeled data for Australia. The length and 
resolution of the data used for the study is novel and offers a high level of confidence in the climatology, the link between the ESI and rainfall and temperature, the long-term trend analysis, and the role of ENSO, IOD, and the SAM on the seasonal and interannual variability of the ESI. Previous studies demonstrated that the ESI is a more complete index to monitor agricultural and flash drought over the United States (Otkin et al. 2013, 2016). The results from the Australian perspective here and from Nguyen et al. (2019) confirm those conclusions and show that it will be a valuable tool to study drought activity throughout Australia at high spatial resolution and over a long period of record. These characteristics promote a deeper understanding of drought in the context of large-scale variability and impact, and ultimately will be useful for realtime drought monitoring and forecasting activities.

Acknowledgments. We warmly thank Stefan Zieger for his crucial computing assistance and Scott Power and Catherine de Burgh-Day for their internal review that helped significantly improve the manuscript. We also thank the three anonymous reviewers for their very constructive comments that further helped improve the manuscript. This work has primarily been supported by the Northern Australian Climate Program (NACP, http://www.bom.gov.au/research/projects/NACP/), funded by Meat and Livestock Australia, the Queensland Government and the University of Southern Queensland. The NACP is coordinated by USQ's Roger Stone. Pandora Hope was partially supported by the Earth Systems and Climate Change Hub of the Australian Government's National Environmental Science Program.

\section{APPENDIX}

\section{CDI and ESI Density Distribution}

Figure A1 is a schematic describing the construction of the CDI. Figure A2 shows the density distribution of the ESI for the NRM clusters over the two periods of 1975-96 and 1997-2018.

\section{REFERENCES}

Anderson, M. C., J. M. Norman, J. R. Mecikalski, J. A. Otkin, and W. P. Kustas, 2007: A climatological study of evapotranspiration and moisture stress across the continental U.S. based on thermal remote sensing. II. Surface moisture climatology. J. Geophys. Res., 112, D11112, https://doi.org/10.1029/2006JD007507.

—, C. Hain, B. Wardlow, A. Pimstein, J. R. Mecikalski, and W. P. Kustas, 2011: Evaluation of drought indices based on thermal remote sensing of evapotranspiration over the continental United States. J. Climate, 24, 2025-2044, https://doi.org/ 10.1175/2010JCLI3812.1.

—, C. R. Hain, J. A. Otkin, X. Zhan, K. Mo, M. Svoboda, B. Wardlow, and A. Pimstein, 2013: An intercomparison of drought indicators based on thermal remote sensing and NLDAS-2 simulations with U.S. Drought Monitor classifications. J. Hydrometeor., 14, 1035-1056, https://doi.org/10.1175/ JHM-D-12-0140.1.

- , and Coauthors, 2016a: The Evaporative Stress Index as an indicator of agricultural drought in Brazil: An assessment based on crop yield impacts. Remote Sens. Environ., 174, 82-99, https://doi.org/10.1016/j.rse.2015.11.034.
— tive stress index and winter wheat and spring barley yield anomalies in the Czech Republic. Climate Res., 70, 215-230, https://doi.org/10.3354/cr01411.

Bureau of Meteorology, 2006: Special Climate Statement 9: An exceptionally dry decade in parts of southern and eastern Australia: October 1996-September 2006. 9 pp., http:// www.bom.gov.au/climate/current/statements/scs9a.pdf.

_- 2019: Special Climate Statement 70 update-Drought conditions in Australia and impact on water resources in the Murray-Darling Basin. 18 pp., http://www.bom.gov.au/climate/ current/statements/scs70.pdf.

Christian, J. I., J. B. Basara, J. A. Otkin, E. D. Hunt, R. A. Wakefield, P. X. Flanagan, and X. Xiao, 2019: A methodology for flash drought identification in gridded datasets: Application of flash drought frequency across the United States. J. Hydrometeor., 20, 833-846, https://doi.org/10.1175/JHM-D-18-0198.1.

CSIRO and Bureau of Meteorology, 2015: Climate Change in Australia Information for Australia's Natural Resource Management Regions. Tech. Rep., CSIRO and Bureau of Meteorology, Australia, 222 pp., http://www.climatechangeinaustralia.gov.au.

Duke, N. C., and Coauthors, 2017: Large-scale dieback of mangroves in Australia's Gulf of Carpentaria: A severe ecosystem response, coincidental with an unusually extreme weather event. Mar. Freshwater Res., 68, 1816-1829, https://doi.org/ 10.1071/MF16322.

Frost, A. J., A. Ramchurn, and A. Smith, 2018: The Australian Landscape Water Balance model (AWRA-L v6): Technical description of the Australian Water Resources Assessment Landscape model version 6. Bureau of Meteorology Tech. Rep., 50 pp., http://www.bom.gov.au/water/landscape/assets/ static/publications/AWRALv6_Model_Description_Report.pdf.

Hendon, H. H., D. W. J. Thompson, and M. C. Wheeler, 2007: Australian rainfall and surface temperature variations associated with the Southern Hemisphere annular mode. J. Climate, 20, 2452-2467, https://doi.org/10.1175/JCLI4134.1.

IPCC, 2014: Climate Change 2014: Synthesis Report. R. K. Pachauri et al., Eds., IPCC, 151 pp., http://www.ipcc.ch/report/ar5/syr/.

Jones, D. A., W. Wang, and R. Fawcett, 2009: High-quality spatial climate data-sets for Australia. Aust. Meteor. Oceanogr. J., 58, 233-248, https://doi.org/10.22499/2.5804.003.

Lloyd-Hughes, B., and M. A. Saunders, 2002: A drought climatology for Europe. Int. J. Climatol., 22, 1571-1592, https:// doi.org/10.1002/joc. 846 .

Marshall, G. J., 2003: Trends in the southern annular mode from observations and reanalyses. J. Climate, 16, 4134-4143, https:// doi.org/10.1175/1520-0442(2003)016<4134:TITSAM>2.0.CO;2.

McKee, T. B., N. J. Doesken, and J. Kleist, 1993: The relationship of drought frequency and duration of time scales. Eighth Conf. on Applied Climatology, Anaheim, CA, Amer. Meteor. Soc., 179-186.

McVicar, T. R., and Coauthors, 2012: Global review and synthesis of trends in observed terrestrial near-surface wind speeds: Implications for evaporation. J. Hydrol., 416-417, 182-205, https://doi.org/10.1016/j.jhydrol.2011.10.024.

Meyers, G., P. McIntosh, L. Pigot, and M. Pook, 2007: The years of El Niño, La Niña, and interactions with the tropical Indian Ocean. J. Climate, 20, 2872-2880, https://doi.org/10.1175/ JCLI4152.1.

Nguyen, H., M. C. Wheeler, J. A. Otkin, T. Cowan, A. Frost, and R. Stone, 2019: Using the evaporative stress index to monitor flash drought in Australia. Environ. Res. Lett., 14, 064016, https://doi.org/10.1088/1748-9326/ab2103. 
Nicholls, N., 2004: The changing nature of Australian droughts. Climatic Change, 63, 323-336, https://doi.org/10.1023/B:CLIM. 0000018515.46344.6d.

Otkin, J. A., M. C. Anderson, C. Hain, I. Mladenova, J. Basara, and M. Svoboda, 2013: Examining rapid onset drought development using the thermal infrared based Evaporative Stress Index. J. Hydrometeor., 14, 1057-1074, https://doi.org/10.1175/ JHM-D-12-0144.1.

—_ and Coauthors, 2016: Assessing the evolution of soil moisture and vegetation conditions during the 2012 United States flash drought. Agric. For. Meteor., 218-219, 230-242, https://doi.org/ 10.1016/j.agrformet.2015.12.065.

_- , Y. Zhong, D. Lorenz, M. C. Anderson, and C. Hain, 2018a: Exploring seasonal and regional relationships between the Evaporative Stress Index and surface weather and soil moisture anomalies across the United States. Hydrol. Earth Syst. Sci., 22, 5373-5386, https://doi.org/ 10.5194/hess-22-5373-2018.

, M. Svoboda, E. D. Hunt, T. W. Ford, M. C. Anderson, C. Hain, and J. B. Basara, 2018b: Flash droughts: A review and assessment of the challenges imposed by rapid onset droughts in the United States. Bull. Amer. Meteor. Soc., 99, 911-919, https://doi.org/10.1175/BAMS-D-17-0149.1.
Rayner, N. A., D. E. Parker, E. B. Horton, C. K. Folland, L. V. Alexander, D. P. Rowell, E. C. Kent, and A. Kaplan, 2003: Global analyses of sea surface temperature, sea ice, and night marine air temperature since the late nineteenth century. J. Geophys. Res., 108, 4407, https://doi.org/10.1029/2002JD002670.

Reisinger, A., and Coauthors, 2014: Australasia. Climate Change 2014: Impacts, Adaptation, and Vulnerability. Part B: Regional Aspects, V. R. Barros et al., Eds., Cambridge University Press, 1371-1438.

Risbey, J. S., M. J. Pook, P. C. McIntosh, M. C. Wheeler, and H. H. Hendon, 2009: On the remote drivers of rainfall variability in Australia. Mon. Wea. Rev., 137, 3233-3253, https://doi.org/ 10.1175/2009MWR2861.1.

Santoso, A., and Coauthors, 2019: Dynamics and predictability of El Niño-Southern Oscillation: An Australian perspective on progress and challenges. Bull. Amer. Meteor. Soc., 100, 403-420, https://doi.org/10.1175/BAMS-D-18-0057.1.

Schneider, T., P. A. O'Gorman, and X. J. Levine, 2010: Water vapor and the dynamics of climate changes. Rev. Geophys., $\mathbf{4 8}$, RG3001, https://doi.org/10.1029/2009RG000302.

Zhao, M., and H. H. Hendon, 2009: Representation and prediction of the Indian Ocean dipole in the POAMA seasonal forecast model. Quart. J. Roy. Meteor. Soc., 135, 337-352, https:// doi.org/10.1002/qj.370. 